\title{
OPTIMALISASI PEMANFAATAN LABORATORIUM BAHASA DALAM MENINGKATKAN PEMBELAJARAN BAHASA ARAB
}

\author{
Ahmadi $^{1}$ \\ ملخص \\ كان استخدام الوسائل التعليمية في التدريس يأتى بتأثر عظيم نخو الطلاب. \\ فلا بد لكل مدرس ان يهتم في اختيار الوسائل اهتماما كبيرا تشمل عليها السمعية \\ والبصرية والتحركية. وهذه الحالة تغرض على السهولة في التدريس والفهم عن المادة. كان \\ معمل اللغوى هو من احد الوسائل التعلمية المستخدم في تدريس اللغة العربية. له منافع \\ عظيمة في اكتساب اللغة بحيث يتحرك كل الاعضاء الجسمية والحسية واشترك كثير من \\ المدارس والمعاهد والجامعات في استخدامه.
}

Kata Kunci : Laboratorium Bahasa, Pembelajaran Bahasa Arab

\section{A. Pendahuluan}

Penelitian tentang pemanfataan media dalam pembelajaran menunjukkan dampak yang sangat signifikan terhadap kemampuan pembelajar memahami materi dibandingkan dengan system conventional instruction. Pembelajaran yang hanya berdasarkan ceramah akan membantu pembelajar memahami materi hingga 5\%. Jika mereka membaca, prosentasi akan meningkat menjadi $10 \%$, berturut-turut audio-visual, demontrasi, diskusi, latihan dan saling mengajar akan mencapai mulai 20\% hingga 80\%. (Yusring, 2007 : 121).

Pakar pendidikan modern, Bobbi de Porter dan Mike Hernacki, juga menjelaskan pentingnya media dalam sebuah pembelajaran dan menyarankan agar seorang pengajar memilih media yang mencakup aspek penglihatan (visual), pendengaran (audio) dan gerak (motorik), karena selain bertujuan memudahkan peserta didik dalam belajar juga mampu menanamkan konsep. Semakin banyak indera dan gerak anak yang terlibat dalam proses pembelajaran maka akan semakin mudah anak mendapatkan sebuah pembelajaran yang bermakna (Bobbi dan Mike, $2002: 31$ ).

Salah satu media yang efektif dan banyak digunakan dalam pembelajaran bahasa - termasuk bahasa Arab - adalah laboratorium bahasa. Meskipun peralatannya dapat dikatakan relatif mahal, tetapi hal tersebut barangkali

${ }^{1}$ Penulis adalah Dosen Bahasa Arab pada Prodi PBA STAIN Palangka Raya. 
berbanding lurus dengan manfaat yang bisa diraih dari laboratorium bahasa sebagai media pembelajaran, sehingga banyak lembaga pendidikan yang menggunakan media ini dalam proses belajar mengajar bahasa.

Hal mendasar yang seringkali menjadi persoalan dalam konteks ini pada sebuah lembaga adalah minimnya sumber daya manusia yang mampu memanfaatkan media ini secara maksimal, kalaupun ada jumlahnya sangat sedikit. Bahkan banyak di antara guru bahasa yang belum mampu memanfaatkannya secara optimal, sehingga tidak mengherankan bila kemudian banyak di antaranya dari media ini yang dibiarkan menganggur begitu saja karena persoalan ketidakmampuan instruktur dalam mengoperasikannya.

Tulisan ini akan membahas tentang pemanfaatan laboratorium bahasa untuk pembelajaran bahasa Arab serta hal-hal terkait dengan laboratorium bahasa itu sendiri antara lain urgensi laboratorium bahasa dalam pembelajaran bahasa Arab, kelebihan dan kekurangan serta langkah-langkah atau teknis operasional penggunaan laboratorium bahasa dalam proses pembelajaran bahasa Arab.

\section{B. Urgensi Laboratorium Bahasa sebagai Media Pembelajaran Bahasa Arab}

Laboratorium atau yang disebut dalam bahasa Arab معْْمَل identik dengan tempat mengadakan percobaan, penyelidikan atau pengujian dan lain sebagainya yang berhubungan dengan fisika, kimia, bahasa dan lain-lain (Abdul Gaffar, 2002 : 197).

Senada dengan penjelasan di atas, secara lebih rinci dikemukakan bahwa laboratorium atau dalam bahasa Inggris laboratory adalah "a room or building where research or scienctific experimentation is carried out; a place where drugs, chemical, etc are prepared; a place for testing, analyzing and demonstrating techniques, theories and methods as in education and social studies" (Siregar, 1997 : 788), (sebuah tempat untuk mengadakan penelitian atau percobaan sains; tempat untuk mengolah obat-obatan, bahan kimia dan sejenisnya; tempat untuk menguji, menganalisa dan mendemonstrasikan teknik, teori atau metode pengajaran dan studi sosial).

Laboratorium bahasa mengacu kepada seperangkat peralatan elektronik audio video yang terdiri atas instructor console sebagai mesin utama, dilengkapi dengan repeater language learning machine, tape recorder, DVD player, video monitor, headset dan students booth yang dipasang dalam satu ruang kedap suara. Selain itu ada pula komponen komputer multimedia sebagai komponen tambahan yang dapat dikombinasikan dengan kesemuanya itu (Haryanto, 2008).

Laboratorium bahasa multimedia yang sekarang banyak digunakan merupakan terobosan baru dan modern. Artinya, peralatan laboratorium bahasa itu mencakup berbagai jenis media dengan fungsi masing-masing yang bervariasi. Guru yang kreatif dapat memanfaatkan laboratorium bahasa multimedia dengan aneka jenis program pelajaran bahasa Arab baik yang dikemas dalam bentuk kaset audio, video, maupun CD interaktif. Bahkan, dengan peralatan ini guru juga dapat memanfaatkan kemampuan dirinya dalam memfasilitasi siswa agar terlibat dalam proses komunikasi secara aktif melalui headset dan microphone yang tersedia pada masing-masing tempat/meja pembelajar. 
Dengan sarana audio-video dan komputer multimedia, secara logis laboratorium bahasa seyogyanya mampu memberikan nilai tambah bagi efektifitas proses pembelajaran bahasa Arab, karena pembelajar dapat mengambil referensi penutur asli. Ini berbeda dengan pembelajaran tanpa laboratorium bahasa di mana pembelajar hanya disuguhi suara non-native speaker yang pada umumnya masih berupa bahasa antara (interlanguage). Kegagalan meningkatkan efektifitas pembelajaran melalui laboratorium bahasa biasanya diakibatkan oleh faktor human error atau management error yang belum memungkinkan laboratorium bahasa beroperasi secara maksimal.

Sebagai sebuah media, laboratorium bahasa dalam konteks pembelajaran bahasa mempunyai fungsi umum sebagai berikut :

\section{Fahm al-Masmû'}

Cara klasik penggunaan piranti laboratorium bagi pembelajaran bahasa Arab adalah untuk pembelajaran istimâ' (listening), meskipun dalam perkembangan selanjutnya hal tersebut kemudian dapat diintegrasikan dengan kalâm, kitâbah maupun qirâ'ah. Sasaran yang mesti dicapai dengan penggunaan laboratorium bahasa di sini adalah agar pembelajar dapat mendengar, melihat, mengamati, dan memahami bagaimana penutur asli (native speaker) menggunakan bahasa asing itu dalam berbagai situasi yang berbeda-beda. Pembelajar akan mendengar secara langsung kata dan ungkapan bahasa Arab yang sesungguhnya dari native speaker yang barangkali akan berbeda keakuratannya bila kata atau ungkapan tersebut disampaikan oleh guru, mengingat adanya perbedaan bahasa, dialek dan sebagainya. Selain itu, siswa juga akan melihat secara langsung ekspresi pembicara pada saat berbicara dan tentu saja menjadi pengalaman belajar yang menarik dan tidak membosankan.

Dengan sasaran demikian diharapkan pembelajar mampu meniru model yang diperankan oleh penutur asli. Dengan kata lain, pembelajar dapat secara langsung mengambil referensi asli, dan bukan referensi kedua, ketiga, atau keempat yang cenderung berbeda dalam banyak hal. Untuk mencapai sasaran itu pengajar perlu menyiapkan kaset atau VCD/DVD yang berisi program atau rekaman suara maupun gambar dari penutur asli bahasa Arab.

2. Multi Purpose

Selain fungsi untuk pembelajaran istimâ' sebagaimana dikemukakan di atas, laboratorium bahasa dapat juga digunakan untuk semi immersion program. Dengan sarana audio dan/atau video serta layar lebar [seperti yang terdapat pada laboratorium bahasa UIN Sunan Kalijaga Yogyakarta], laboratorium bahasa dapat dipergunakan untuk menayangkan perkuliahan/ pembelajaran bidang studi lain yang disajikan dalam bahasa sasaran. Sebagai contoh, untuk mahasiswa Jurusan Pendidikan Bahasa, instruktur dapat menayangkan VCD Language Teaching Methods dari Diane LarsenFreeman; untuk mahasiswa jurusan Sastra dapat disajikan film Hamlet, Shakespeare in Love, Ayat-ayat Cinta atau film-film dokumenter.

Tidak tertutup kemungkinan juga bahwa fungsi laboratorium multimedia dapat pula dipergunakan untuk menayangkan perkuliahan/ pelajaran matematika, geografi, antropologi, biologi, sejarah, ekonomi, 
teknik, kedokteran dan lain sebagainya yang disajikan dengan bahasa asing sasaran sepanjang materi pelajaran tersebut tersedia dalam bentuk VCD/DVD, maupun CD-room. Bila hal ini dilakukan, tak ayal pembelajar mengalami program semi immersion di mana semua pelajaran yang diberikan disajikan dalam bahasa sasaran. Program ini bermanfaat dalam dua hal sekaligus; membekali pembelajar dengan pengetahuan yang relevan dengan bidang studi, dan sekaligus membekali mereka dengan keterampilan berbahasa asing melalui proses pembelajaran secara tidak sadar (subconcsious learning).

Dengan program semi immersion tersebut, di masa yang akan datang laboratorium bahasa multimedia tidak saja dapat dimanfaatkan sebagai sarana pembelajaran bahasa asing, akan tetapi sekaligus juga dapat dipergunakan sebagai sarana penunjang bagi perkuliahan/mata pelajaran lain (multiguna).

3. Ujian Standarisasi Bahasa (TOEFL/TOAFL)

Fungsi lain yang dapat manfaatkan dari laboratorium bahasa adalah penunjang program standarisasi kualitas lulusan dengan skor Bahasa Arab tertentu seperti TOAFL (Test of Arabic as a Foreign Language) atau bahasa Inggris seperti TOEFL Prediction, IELTS atau TOEIC. Program ini dapat dilakukan dengan melakukan pelatihan terlebih dahulu dengan materi belajar yang terkemas dalam bentuk kaset audio maupun CD-room. Dengan demikian perguruan tinggi dan masyarakat dapat melihat secara jelas seberapa baik kualitas lulusan yang dihasilkan.

Mencermati ulasan di atas tentang urgensi laboratorium bahasa sebagai media pembelajaran, maka tidaklah berlebihan jika kemudian laboratorium bahasa digunakan sebagai media alternatif untuk dapat menarik minat belajar anak didik dalam sebuah proses pembelajaran, termasuk dalam pembelajaran bahasa Arab.

\section{Kelebihan dan Kekurangan Laboratorium Bahasa sebagai Media}

Setiap media pembelajaran yang digunakan tentu tidak akan terlepas dari berbagai kelebihan dan kekurangan, karena pada prinsipnya tidak ada alat bantu atau media pembelajaran yang sempurna dan selalu tepat guna. Sebuah media dapat menjadi alternatif dan penyempurna bagi media lainnya dan tentu digunakan sesuai dengan kebutuhan pembelajaran.

Secara mendasar kelebihan dan kekurangan laboratorium bahasa sebagai media pembelajaran dapat dilihat sebagai berikut :

1. Kelebihan

a. Pembelajaran di laboratorium bahasa akan menjadi sangat menarik karena menjadi pengalaman lain bagi pembelajar dalam sebuah proses pembelajaran.

b. Dapat menyampaikan suara native speaker sekaligus melihat penampilannya (bila diikuti dengan tayangan film).

c. Program-program pembelajaran sudah banyak tersedia, sehingga tidak merepotkan guru untuk membuatnya. Guru hanya memilih sesuai kebutuhan. 
2. Kekurangan

a. Biayanya mahal dan tidak semua lembaga pendidikan memiliki laboratorium bahasa.

b. Pemanfaatannya memiliki ketergantungan terhadap arus/aliran listrik yang memadai.

c. Memerlukan ruangan khusus yang permanen.

d. Operasionalnya cukup rumit sehingga seorang guru maupun siswa harus terlebih dahulu memiliki pengetahuan dasar menggunakannya dalam pembelajaran.

\section{Langkah-langkah Teknis Pembelajaran Bahasa Arab di Laboratorium Bahasa}

Pembelajaran bahasa Arab yang dilakukan di laboratorium bahasa memerlukan pengetahuan khusus tentang laboratorium bahasa itu sendiri, baik yang menyangkut hardware maupun software-nya. Pengetahuan yang memadai tentang pengoperasian laboratorium bahasa mutlak harus dimiliki seorang pengajar yang ingin memanfaatkan fasilitas ini sebagai media pembelajaran, agar proses pembelajaran dapat berjalan dengan lancar dan tidak mendapatkan kendala-kendala teknis yang dapat mengganggu proses pembelajaran. Kalau tidak, maka akan banyak waktu yang tersita untuk hal-hal di luar esensi pembelajaran.

Pada dasarnya, langkah-langkah teknis pembelajaran bahasa Arab di laboratorium bahasa bersifat fleksibel dan menyesuaikan dengan software yang digunakan. Beberapa tuntunan dasar pembelajaran di laboratorium bahasa dapat penulis uraikan sebagai berikut :

1. Pastikan jumlah peserta/siswa sesuai dengan tempat duduk yang tersedia di laboratorium bahasa, kalau jumlah peserta banyak dapat dibagi ke dalam beberapa kelompok.

2. Ajarkan peserta tentang operasional laboratorium bahasa dalam pembelajaran (meskipun hanya secara singkat) agar tidak terjadi kebingungan dalam pengoperasiannya pada saat proses berlangsung.

3. Tentukan materi pembelajaran dan sebaiknya guru terlebih dahulu memberikan gambaran tentang materi yang akan diajarkan kepada siswa. [apakah untuk pembelajaran istimâ', kalâm atau aspek lainnya).

4. Siapkan program yang dipilih [kaset audio, VCD/DVD player atau program pembelajaran yang sudah tersedia di komputer server].

5. Setelah semua komponen (guru, siswa dan alat) siap, maka pembelajaran dapat mulai dengan menjalankan program/software sebagaimana tersedia pada laboratorium bahasa.

6. Dalam proses pembelajaran, usahakan semua peserta mendapat perhatian dan kesempatan yang sama, baik bertanya, menjawab, berdiskusi dan sebagainya.

7. Setelah pembelajaran selesai, guru dapat saja mendiskusikan ulang dengan siswa tentang pelajaran yang telah diajarkan tanpa menggunakan peralatan laboratorium bahasa. 
Salah satu contoh program/software yang digunakan di laboratorium bahasa UIN Sunan Kalijaga Yogyakarta [sebagaimana pengalaman penulis] adalah program SANAKO TANDBERG EDUCATIONAL yang dibuat oleh PT. VISICOM CITRA PERKASA JAKARTA yang operasionalnya kurang lebih sebagai berikut :

Demikian uraian singkat tentang operasionalisasi laboratorium bahasa sebagaimana yang digunakan di laboratorium bahasa UIN Sunan Kalijaga Yogyakarta yang berkenaan dengan alat-alat, fungsi dan proses pelaksanaannya. Langkah-langkah sebagaimana yang telah dikemukakan di atas secara teoritis memang cukup rumit untuk dilakukan, akan tetapi bila dipelajari dan praktekkan berulang-ulang tentu saja akan menjadi mudah.

Akan terjadi beberapa perbedaan dalam pengoperasian laboratorium bahasa apabila software yang digunakan berbeda, seperti halnya [sebagaimana observasi penulis] di STAIN Palangka Raya yang menggunakan program LABTECH di laboratorium bahasa-nya. Meskipun memiliki prinsip-prinsip dasar yang relatif sama dengan program SANAKO, tetapi pada beberapa item program ada yang berbeda.

Pada laboratorium bahasa STAIN Palangka Raya yang menggunakan program LABTECH, ruangan cukup besar dengan kapasitas 44 (empat puluh empat) meja untuk peserta/mahasiswa, sesuai dengan kapasitas program. Meskipun demikian, menurut pengelola laboratorium bahasa tersebut bahwa dalam penggunaannya hampir tidak pernah sepenuhnya digunakan, maksimal 30 - 35 mahasiswa saja. Kelas yang begitu besar dengan jumlah siswa/ mahasiswa yang banyak menurut hemat penulis memang akan membuat pembelajaran menjadi kurang efektif, karena tidak semua peserta akan mendapat perhatian maksimal dari guru. Semakin sedikit jumlah peserta pengguna laboratorium bahasa, maka tentu saja akan semakin baik dan efektif pembelajaran bahasa yang dilakukan, karena peserta akan memiliki kesempatan yang lebih banyak. Idealnya, pembelajaran bahasa Arab di laboratorium bahasa diikuti sebanyak 10 - 15 siswa/mahasiswa saja.

Secara singkat dapat penulis gambarkan master console LABTECH laboratorium bahasa STAIN Palangka Raya sebagai berikut :

\section{E. Penutup}

Salah satu penyebab munculnya asumsi bahwa belajar bahasa Arab itu sulit disebabkan kurang optimalnya penggunaan media dalam pembelajarannya, sehingga nampak monoton dan kurang menarik. Pembelajaran bahasa Arab di laboratorium bahasa dapat menjadi alternatif bagi pengajar untuk menggunakannya sebagai media pembelajaran bahasa Arab.

Perkembangan dunia teknologi komunikasi dan informasi dewasa ini seyogyanya mampu dimanfaatkan guru/dosen dalam melaksanakan proses pembelajaran yang efektif dan efisien. Begitupun dengan laboratorium bahasa sebagai sebuah media pembelajaran bahasa Arab, seyogyanya mampu dimanfaatkan untuk peningkatan kualitas pembelajaran bahasa Arab. Aspek human error dan keterbatasan kemampuan dalam operasionalnya dapat diminimalisir dengan mengikuti pelatihan penggunaan laboratorium bahasa bagi 
guru/dosen bahasa, sehingga laboratorium bahasa dapat digunakan secara optimal. 


\section{DAFTAR PUSTAKA}

A.E. Siregar, et. al., Kamus Lengkap Indonesia - Inggris, Jakarta : PT. Raja Grafindo Persada, 1997.

Abdul Ghoffar, Kamus Indonesia - Arab : Istilah Umum dan Kata-kata Populer, Jakarta : PT. Raja Grafindo Persada, 2000.

Bobbi de Porter \& Mike Hernacki, Quantum Learning : Membiasakan Belajar Nyaman dan Menyenangkan, Bandung : Kaifa, 2002.

Haryanto Atmowardoyo, Laboratorium Bahasa Multimedia dan Fungsinya dalam Pembelajaran Bahasa Asing dalam http://google/com. diakses tanggal 17 Mei 2008.

Tim Penyusun Pedoman Praktik Bahasa Asing di Laboratorium Bahasa, Pedoman Praktik Bahasa Asing di Laboratorium Bahasa STAIN Palangka Raya. Palangka Raya : Tidak Diterbitkan, 2006.

Sanako Tandberg Educational Program [digunakan di laboratorium bahasa UIN Sunan Kalijaga Yogyakarta], 2008.

Yusring Sanusi Baso, "Computer Assisted Language Learning (CALL), Program Pembelajaran Multimedia Interaktif untuk Bahasa Arab" dalam Seminar Internasional Bahasa Arab dan Sastra Islam : Kurikulum dan Perkembangannya, Dudung Rahmat Hidayat dan Yayan Nurbayan (ed). Bandung : Tanpa Penerbit, 2007. 